\title{
Exogenous insulin antibody syndrome (EIAS): a clinical syndrome associated with insulin antibodies induced by exogenous insulin in diabetic patients
}

\author{
Xiaolei Hu ${ }^{1,2}$ and Fengling Chen ${ }^{2}$ \\ ${ }^{1}$ Department of Endocrinology, The First Affiliated Hospital of Bengbu Medical College, Bengbu, Anhui, China \\ ${ }^{2}$ Department of Endocrinology, Shanghai Ninth People's Hospital, Shanghai Jiao Tong University School of Medicine, Shanghai, China \\ Correspondence should be addressed to F Chen: cfl1993@126.com
}

\begin{abstract}
Insulin has been used for diabetes therapy and has achieved significant therapeutic effect. In recent years, the use of purified and recombinant human insulin preparations has markedly reduced, but not completely suppressed, the incidence of insulin antibodies (IAs). IAs induced by exogenous insulin in diabetic patients is associated with clinical events, which is named exogenous insulin antibody syndrome (EIAS). The present review is based on our research and summarizes the characterization of IAs, the factors affecting IA development, the clinical significance of IAs and the treatments for EIAS.
\end{abstract}

\author{
Key Words \\ - insulin antibodies \\ - exogenous insulin \\ antibody syndrome \\ - diabetes \\ - hypoglycaemia \\ - hyperglycaemia
}

\section{Introduction}

Since insulin was discovered by Banting and Best in the 1920s, it has been used for diabetes therapy and has achieved significant therapeutic effects. However, some immunological responses to exogenous insulin have been found (1). It was first reported by Berson and coworkers (2) that clinical hypersensitivity and insulin resistance were associated with circulating insulin antibodies (IAs) in patients receiving exogenous animal insulin therapy. Over the past few decades, with the wide use of human insulin, several clinical trials have revealed that the human insulin preparation can also induce IAs, although to a lesser extent than does animal insulin $(3,4,5)$. In recent years, the use of purified and recombinant human insulin preparations has markedly reduced, but not completely suppressed, the incidence of IAs. Sporadic case reports have been published regarding individuals whose serum had high titre IAs while being treated with recombinant human insulin or human insulin analogues (1), especially in Asian populations $(6,7,8,9,10,11,12)$.

Different from insulin autoimmune syndrome (IAS, also called Hirata disease), which is a condition characterized by spontaneous hypoglycaemia and is associated with the presence of insulin autoantibodies in patients without previous insulin exposure (13), IAs induced by exogenous insulin in diabetic patients is associated with clinical events, such as hypersensitivity reactions, pregnancy, glycaemia variability and metabolic control (1), and mainly with insulin resistance/ hyperglycaemia $(6,10,14,15,16)$ or hypoglycaemia $(6,7,8,10,17,18)$. Therefore, we named this condition exogenous insulin antibody syndrome (EIAS). Recently, we reported 12 cases of patients with EIAS in which the clinical characteristics and IA pharmacokinetic parameters were analysed, and all of the patients
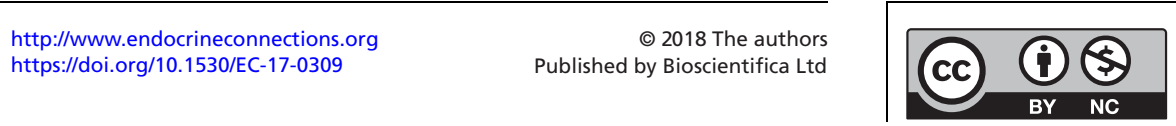
subsequently received effective treatment (10). The present review is based on our research and summarizes the characterization of IAs, the factors affecting IA development, the clinical significance of IAs and the treatments for EIAS.

\section{Characterization of IAs}

IAs' representatives are found in all of the Ig classes. Among them, IgG is predominant $(19,20)$, although IgM, IgA and IgE have also been described $(21,22,23,24)$. The relationship between Ig class and clinical manifestation is debated. Grammer and coworkers reported that IgG was associated with cases of severe insulin resistance (23). IgM was detected during early insulin treatment and reported in patients with immunological insulin resistance (19, 25). Several reports regarding allergic reactions have implicated a role of $\operatorname{IgA}$ or IgE alone or in combination with $\operatorname{IgG}(22,23,24,26,27)$. However, other studies found no correlations between Ig presence and allergic reactions $(28,29,30)$.

The two classic techniques used to measure IAs are enzyme-linked immunosorbent assay (ELISA) and radioligand-binding assay (RBA). The differences between ELISA and RBA measurements have been attributed to inherent differences in assay formats. ELISA reaches a stage of excess antigens through the use of progressively diluted serum; thus, IAs of varying affinities are measured with this assay $(31,32)$. In contrast, RBA is a solution-based assay in which low levels of ${ }^{125}$ I-labelled insulin are used; thus, this assay primarily measures high-affinity IAs $(31,32)$. The radioimmunoassay (RIA) has been used to measure the amount of IAs via Scatchard plots analysis (33). In addition, Kure and coworkers and Trabucchi and coworkers $(34,35)$ performed a trial to establish a new method for the quantitative and qualitative analysis of IAs by using surface plasmon resonance.

Based on the binding affinity and binding capacity of IAs as determined from the apparent linear regions of curvilinear Scatchard plots, IAs can be divided into two populations: low affinity/high capacity and high affinity/low capacity (Fig. 1). The former is commonly found in IAS patients with insulin autoantibodies, w`hich lead to postprandial hyperglycaemia and nocturnal hypoglycaemia, whereas the latter is associated with EIAS, which is typically accompanied by severe insulin resistance (1).

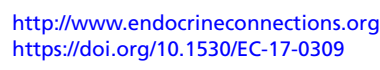

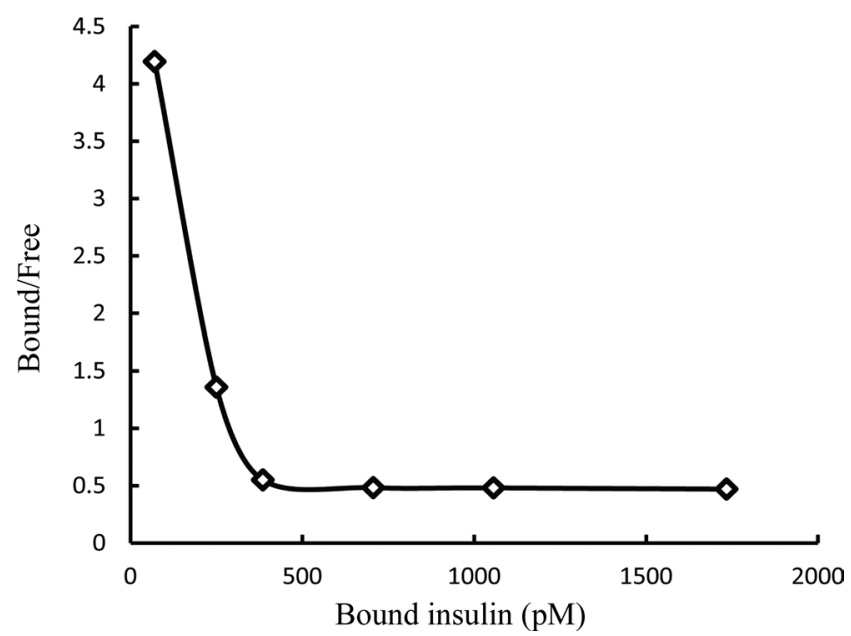

Figure 1

Representative images of Scatchard plots of insulin antibodies in one of our patients with EIAS. The insulin antibodies-binding data showed bimodal distributions, suggesting two classes of antibodies characterized by the high-affinity/low-capacity and low-affinity/high-capacity sites (11). Bound: bound insulin, Free: free insulin.

\section{Factors affecting IA development}

\section{Formulation of insulin}

There are three types of insulin: animal insulin, including bovine and porcine insulin, recombinant human insulin and insulin analogues. Because the amino acid sequences of animal insulin are different from those of human insulin, the immunogenicity of animal insulin is higher (36). Although the amino acid sequence of recombinant human insulin is consistent with that of human insulin, it can induce IAs, with exogenous insulin being immunogenic (37). Insulin analogues, including rapid-acting and long-acting human insulin analogues, are similar to human insulin in molecular structure. Their amino acid sequences have been slightly adjusted or modified. Several studies have found no significant difference in the IAs induced by subcutaneous injection of rapid-acting human insulin analogues and recombinant human insulin $(38,39,40,41)$.

In a large-scale clinical trial of patients with clinically diagnosed type 1 diabetes who had been receiving insulin therapy for more than 1 year, IA titres did not increase following additional injection with glargine insulin for at least 2 months (42). However, a recent study by Hattori and coworkers (9) found that glargine and aspart were more antigenic than other insulin analogues. The reasons for these discordant results are not clear but may be attributed to differences in study protocols and the sensitivity of methods for detecting

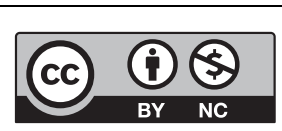

This work is licensed under a Creative Commons Attribution-NonCommercial 4.0 International License. 
IAs. At present, there are no clinical data regarding IA level changes in subjects receiving detemir insulin.

\section{Delivery route of insulin}

Subcutaneous injection is the most common method of insulin administration. Researchers found an increase in IAs during continuous subcutaneous insulin infusion and multiple-injection therapy in comparison with conventional treatment with two daily injections of combined regular and intermediate insulin (43), suggesting that differences in the method of insulin administration can affect IA development. Various studies have found large increases in plasma levels of IAs following the delivery of insulin with implantable insulin pumps (IIPs), leading researchers to suggest potential causative mechanisms such as the storage of insulin in the pump reservoir or the presence of surfactants or polyethylene glycol $(44,45)$. A small, nonrandomized study designed to compare the antigenicity of continuous subcutaneous insulin infusion (CSII) with that of continuous peritoneal insulin infusion (CPII) demonstrated that IAs were increased significantly in the CPII group relative to the CSII group (46). However, according to the recent review from Radermecker and coworkers (47), even if CSII and CPII might promote the development of circulating IAs, this increase did not lead to immunological insulin resistance, compared to that previously described with animal non-purified insulin preparations and seemed to have only marginal influence on blood glucose control or complications in most diabetic patients.

As insulin injection therapy is burdensome for many patients, novel routes of insulin administration are an area of interest in the diabetes field. A potential alternative to the subcutaneous delivery of insulin in the management of diabetes is delivery via inhalation (48). Exubera was the first inhalable insulin approved by the Food and Drug Association (FDA) and the European Medicines Agency (EMEA) and was approved for the treatment of both type 1 and type 2 diabetes in 2006. The other two inhaled insulin systems are the AERx insulin diabetes management system (AERx iDMS) and the AIR insulin system. Studies of the induction of IAs have been conducted with these three types of inhaled insulin. Fineberg and coworkers (20) found that among patients with type 1 diabetes, IA development in an Exubera group exceeded that in a group receiving regular subcutaneous insulin. Similarly, a prospective randomized pharmacodynamic study of inhaled and subcutaneous insulin found that the IA levels of the Exubera group were significantly higher than those of the subcutaneous insulin group (49). Furthermore, another study found that IA levels declined after cessation of Exubera (50). In the AERxiDMS trials, IA levels increased in the inhaled insulin group but remained unchanged in the subcutaneous insulin group (51). The findings of the AIR trials were similar; both Garg SK and Ang E reported that IA levels were significantly greater in the AIR insulin group than in the subcutaneous insulin group $(52,53)$. However, the future of these inhaled insulins is limited: Pfizer announced that it would no longer be selling Exubera secondary to poor sales and acceptance, Novo Nordisk elected to discontinue further study with the AERxiDMS system given the experience of Pfizer with Exubera and Eli Lilly and partners are not pursuing development of the AIR insulin system (48). However, a new inhaled insulin, Afrezza, was recently been approved by the FDA (54). Studies of IA development with this inhaled insulin are needed.

\section{Patient factors}

IAs are partly influenced by genetic factors. Previous studies have found that the presence of histocompatibility leukocyte antigen (HLA)-B15, HLA-DR4 and HLA-DR7 increased the rate of IA formation, whereas the presence of HLA-B8 and HLA-DR3 had the opposite effect $(3,55$, 56). However, another prospective study found no effect of HLA-DR3, HLA-DR4 or their combination on IA formation (57). Recently, four patients from Japan who suffered from EIAS were identified; their HLAs were DRB1*0406, DRB1*090102/150201DQB1*030302/060101, DRB1*130201-DQB1*060401 and DRB1 080302, $090102(6,58,59)$. Age may play an important role in the IA response with exogenous insulin administration. The research of Fineberg and coworkers (60) revealed a 3\% decrease in the risk of IA development for every one-year increase in age, that is to say, the development of IA in response to exogenous insulin was inversely correlated with age. The underlying mechanism is unclear; it is possible that immunological competence declines with age and thereby leads to a decreased ability to generate long-lasting memory cells, delayed hypersensitivity responses and a decreased ability to form IAs. However, most studies addressing patient factors in IA development were conducted in the previous century and used animal insulin (bovine or porcine); thus, new large-scale studies using human insulin are needed. http://www.endocrineconnections.org
https://doi.org/10.1530/EC-17-0309
(C) 2018 The authors Published by Bioscientifica Ltd

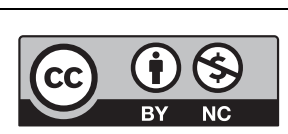

This work is licensed under a Creative Commons Attribution-NonCommercial 4.0 International License. 
Increased insulin resistance and risk of hyperglycaemia

\section{Glycaemic fluctuation}

The main symptom of EIAS is fluctuations in blood glucose; most patients tend to experience hypoglycaemia at night and hyperglycaemia during the day. A smallsize clinical trial from Chinese indicated that the inner daily glucose fluctuation was larger in IA-positive patients than in IA-negative ones (61) largely because of immunological insulin resistance. The IAs combined with exogenous insulin, which induced immunological insulin resistance and led to a higher postprandial peak in blood glucose. However, this combination was reversible: when bound insulin dissociated due to the change in $\mathrm{pH}$ at night, free insulin increased, thus resulting in hypoglycaemia $(6,47,62)$. It is worth noting that the clinical importance of IA causing hypervariability of glycemic control is very rare, even in the Asian populations.

\section{Tampon-like effect}

\section{Binding}
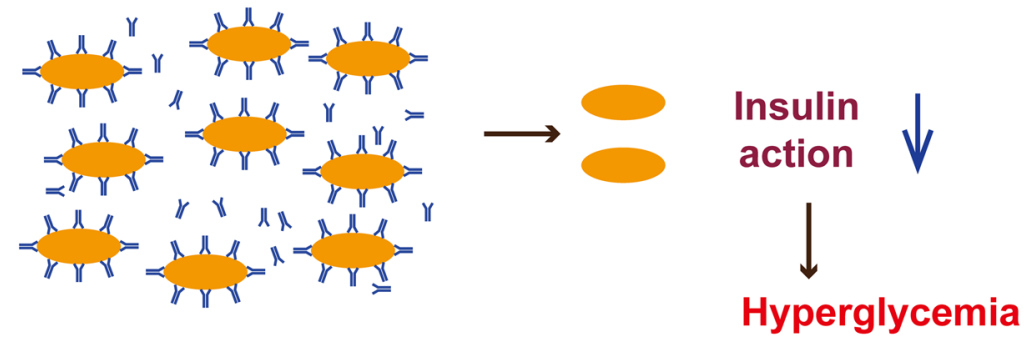

Most studies published in the 1980s and 1990s found no significant relationship between IA and glycated haemoglobin or average glycaemia (1). However, cases of insulin resistance attributed to IAs have been continually reported since 2000, including cases involving patients treated only with human insulin or insulin analogues $(17,63,64,65,66)$. The effects of IAs include their ability to increase insulin resistance and reduce insulin action, thus triggering hyperglycaemia ('tampon-like effect') (47) (Fig. 2). High IA titres have been associated with insulin resistance, reflected by an increase in insulin requirement (15). In a recent study, immune-reactive insulin levels were strongly correlated with IA levels, and elevated fasting immuno-reactive insulin levels were an independent risk factor for coronary heart disease in insulin-treated older adults (67). Furthermore, a recent

\section{Circulation
Cir}

\section{Reservoir-like effect}

Dissociation
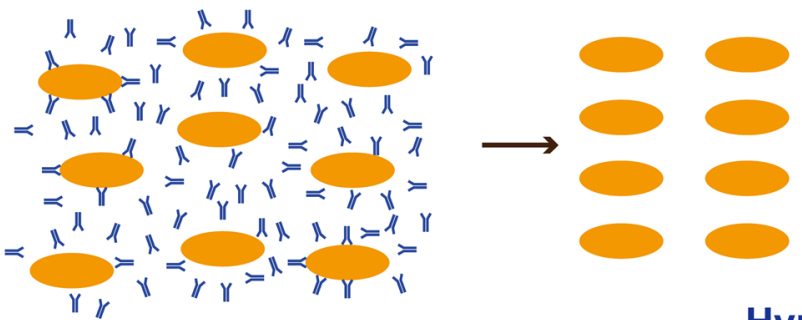

Insulin action

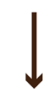

Hypoglycemia
Figure 2

A schematic drawing of IAs' clinical significance. Massive volumes of insulin binding to the insulin antibodies, a marked increase in insulin resistance is induced, insulin antibodies could reduce insulin action, thus triggering hyperglycemia ('tamponlike effect'). On the other hand, insulin antibodies could also enhance and prolong the pharmacodynamic action of insulin by serving as a carrier, when massive volumes of insulin become dissociated, free insulin increases all at once, thus leading to hypoglycaemia ('reservoirlike effect'). http://www.endocrineconnections.org https://doi.org/10.1530/EC-17-0309
(C) 2018 The authors Published by Bioscientifica Ltd

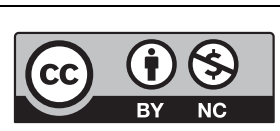

This work is licensed under a Creative Commons Attribution-NonCommercial 4.0 International License. 
clinical trial involving Chinese populations conducted to study the immunogenicity of recombinant human insulin and its clinical significance during treatment of type 2 diabetes mellitus (T2DM) patients indicated that (1) recombinant human insulin has immunogenicity; (2) the serum insulin levels of diabetic patients who have used recombinant human insulin should be routinely measured to test for hyperinsulinaemia and insulin resistance and (3) the presence of IAs is a risk factor for insulin resistance and is associated with the compliance rate of glycated haemoglobin (68). Although insulin resistance has been described in patients with high IA levels, a mechanism underlying their causal relationship has not been clearly established.

\section{Prolongation of insulin action and risk of hypoglycaemia}

Fineberg surmised that there was no relationship between hypoglycaemic event rate and IA level (1); however, recent studies suggest that high levels of IAs can be associated with clinical hypoglycaemia syndromes in a small number of patients $(10,12,17,34,66,69)$. For example, in a recent study, insulin binding to antibodies $>15 \%$ appears to be a strong risk factor for inexplicable severe hypoglycaemias in type 1 diabetic children. Another study found that insulin-receiving individuals with high IA levels and recurrent hypoglycaemia had a higher dissociation constant for insulin than for monoclonal antibodies to human insulin, as measured by surface plasmon resonance; furthermore, this study reported that IA characteristics were among the causative factors in hypoglycaemic episodes (34). To date, two clinical studies have been conducted with our patients with diabetes. One study found that the occurrence of hypoglycaemia was significantly higher in IA-positive patients than that in IA-negative ones (68); the other found that the characteristics of immunological hypoglycaemia were associated with IAs induced by exogenous insulin (12). The reasons for these differing results from those of previous studies are not clear but might reflect study differences in study protocols, subjects and the sensitivity of methods for detecting IAs. IAs could enhance and prolong the pharmacodynamic action of insulin by serving as a carrier ('reservoir-like effect') (Fig. 2); presumably, antibodies first bind the insulin in circulation and later dissociate from the insulin, allowing the activation of cellular insulin receptors and leading to unexpected hypoglycaemia (47).

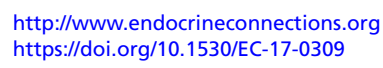

\section{Other relationships}

In addition to the above-described clinical manifestations, clinical issues such as pregnancy and diabetic complications have been shown to be related to IAs. Some early studies suggested that IAs were associated with increases in neonatal morbidity, including hypoglycaemia, respiratory distress syndrome and hypocalcaemia (70, 71). However, studies in which pregnant women with diabetes were monitored for glycaemic control argue against a relationship between IAs and foetal risk, with no distinguishing clinical characteristics of neonatal hypoglycaemia found to be associated with IAs (1). Moreover, the majority of human studies have shown no relationship between IAs and diabetic microangiopathic complications, including nephropathy, retinopathy and neuropathy (1).

\section{Treatments for EIAS}

Discontinuation of insulin or combination of oral hypoglycaemic agents

IAs have a long half-life in the body. A small prospective research study demonstrated that IA levels gradually decrease within 1 month after insulin withdrawal but that the full disappearance of IAs can require more than 1 or 2 years (72). It has been reported that metformin combined with an $\alpha$-glucosidase inhibitor can significantly lower plasma IA concentrations. In addition, a combination of liraglutide and sulfonylurea has been reported as a treatment for type 2 diabetic patients with high titres of IAs produced by exogenous insulin (58). Potential explanations for these observations are as follows: sulfonylurea may stimulate the production of free insulin or reduce the binding capacity of IAs and insulin; metformin may strengthen the action of free insulin and promote the dissociation of insulin immune complexes; and GLP-1 receptor agonists, as potent stimulators of insulin secretion, especially in combination with sulfonylurea, can enhance the role of insulin when in this combination (Table 1).

\section{Replacement of insulin formulations}

Because the immunogenicity of human insulin is less than that of animal insulin, before the advent of insulin analogues, the primary treatment for EIAS in clinical practice was generally to switch the insulin formulation 
Table 1 Reported treatments for EIAS.

Treatments
Metformin $+\alpha$-glucosidase inhibitor
Liraglutide + sulfonylurea
Sulfonylurea/ $\alpha$-glucosidase inhibitor
Lispro
Glulisine
Glargine
Glucocorticoids
Immunosuppressants
Immunosuppressive
Medical nutrition therapy

\begin{tabular}{r} 
References \\
\hline 10 \\
57 \\
65 \\
64 \\
8,74 \\
42 \\
$75,76,77$ \\
$6,17,78$ \\
79 \\
11
\end{tabular}

to human insulin. Previous research has shown that human insulin can be considered an alternative treatment in cases of immune-mediated insulin resistance induced by animal insulin (73). It is well known that the insulin analogues have lower immunogenicity than animal/ human insulin; accordingly, replacement with an insulin analogue is an effective method for the treatment of EIAS. For example, (1) insulin lispro reduced IAs in a patient with type 2 diabetes with immunological insulin resistance (64); (2) insulin glulisine can ameliorate nocturnal hypoglycaemia related to IAs (8); (3) diabetic ketosis caused by IAs induced by the insulin analogue aspart was successfully treated with the insulin analogue glulisine (74) and (4) results from a multinational, randomized parallel group clinical trial showed that treatment with glargine in patients previously treated with insulin for at least 1 year did not result in increased insulin antibody levels (42), which suggested that treatment with glargine was feasible. However, a recent study by Hattori and coworkers (9) found that glargine and aspart were more antigenic than other insulin analogues. The reasons for these discordant results are unclear but might be due to study differences in study protocols and the sensitivity of methods for detecting IAs.

\section{Administration of glucocorticoids, immunosuppressants, plasmapheresis and other treatments}

EIAS is an immune disease and can, therefore, be treated with glucocorticoids or immunosuppressants. Several studies have reported that patients with hypoglycaemia and hyperglycaemia due to IAs against therapeutic human insulin can be successfully treated with prednisolone $(75,76,77)$. Immunosuppressants such as mycophenolate mofetil (78) and cyclophosphamide (6) are also used to treat EIAS. Ishizuka and coworkers (6) encountered two patients who developed daytime hyperglycaemia and early morning hypoglycaemia because of IAs. To decrease their IA levels, one patient was administered $40 \mathrm{mg} /$ day of prednisolone and added cyclophosphamide (300 mg/month) pulse therapy, and the other patient underwent double filtration plasmapheresis (DFPP) and received oral administration of prednisolone ( $40 \mathrm{mg} /$ day) and cyclophosphamide ( $300 \mathrm{mg} / \mathrm{month})$ pulse therapy to suppress IA production due to a very poor blood glucose profile. In addition, Koyama and coworkers (17) successfully treated two diabetic patients with hypoglycaemia and hyperglycaemia due to insulin antibodies against therapeutic human insulin using plasmapheresis and prednisolone. The exact mechanism of action was unclear; however, glucocorticoids may inhibit insulin antibody production or promote insulin antibody immune complex dissociation. Furthermore, immunosuppressive agents, such as cyclophosphamide and mycophenolate mofetil, may specifically inhibit $\mathrm{T}$ and $\mathrm{B}$ cells and thereby reduce the production of IAs. In addition, for patients with high IAA titres showing no response to steroid therapy, intramuscular immunoglobulin one time per week was found to be an effective treatment (79). Recently, a rare case report demonstrated that medical nutrition therapy was effective in the management of hypoglycaemia caused by IAs, which expands our knowledge of the management of hypoglycaemia and highlights the significance of nutritional and lifestyle interventions in the treatment of IA-induced hypoglycaemia (11).

\section{Conclusion}

With the wide use of purified and recombinant human insulin preparations, the incidence EIAS has gradually decreased. However, the literature and our own experience indicate that the production of IAs in patients with diabetes mellitus continues, especially in Asian populations. Evidence that IAs induced by exogenous insulin therapy can cause clinical significance is limited to case reports, but IA production does greatly affect glycaemic control according to our research (10). Type 2 diabetic patients receiving long-term recombinant human insulin treatment who have unexplained high plasma glucose or frequent reoccurrence of hypoglycaemia should be investigated for the presence of EIAS. Administration of prednisone, changing insulin formulations or discontinuing insulin and switching to oral antidiabetic agents are effective treatments of EIAS.

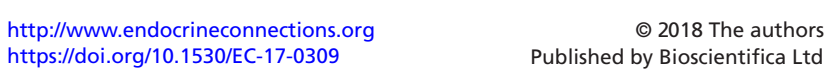


Declaration of interest

The authors declare that there is no conflict of interest that could be perceived as prejudicing the impartiality of this review.

\section{Funding}

This work received the support of the National Nature Science Foundation of China (Grant No. 81670735), the Natural Science Foundation of Anhui Province (Grant No. 1508085SQH220) and the General Practice Clinical Research Project of Health and Family Planning Commission of Anhui Province (Grant No. 2016QK021).

\section{Author's contribution statement}

$\mathrm{H} X \mathrm{~L}$ has written, edited and submitted this manuscript. C F L has edited and approved this manuscript.

\section{References}

1 Fineberg SE, Kawabata TT, Finco-Kent D, Fountaine RJ, Finch GL \& Krasner AS. Immunological responses to exogenous insulin. Endocrine Reviews 200728 625-652. (https://doi.org/10.1210/er.2007-0002)

2 Berson SA, Yalow RS, Bauman A, Rothschild MA \& Newerly K. Insulin-I131 metabolism in human subjects: demonstration of insulin binding globulin in the circulation of insulin treated subjects. Journal of Clinical Investigation 195635 170-190. (https://doi. org/10.1172/JCI103262)

3 Schernthaner G, Borkenstein M, Fink M, Mayr WR, Menzel J \& Schober E. Immunogenicity of human insulin (Novo) or pork monocomponent insulin in HLA-DR-typed insulin-dependent diabetic individuals. Diabetes Care 19836 (Supplement 1) 43-48.

4 Fineberg SE, Galloway JA, Fineberg NS, Rathbun MJ \& Hufferd S Immunogenicity of recombinant DNA human insulin. Diabetologia 198325 465-469.

5 Heding LG, Marshall MO, Persson B, Dahlquist G, Thalme B, Lindgren F, Akerblom HK, Rilva A, Knip M, Ludvigsson J, et al. Immunogenicity of monocomponent human and porcine insulin in newly diagnosed type 1 (insulin-dependent) diabetic children. Diabetologia 198427 (Supplement) 96-98. (https://doi.org/10.1007/ BF00275658)

6 Ishizuka T, Ogawa S, Mori T, Nako K, Nakamichi T, Oka Y \& Ito S. Characteristics of the antibodies of two patients who developed daytime hyperglycemia and morning hypoglycemia because of insulin antibodies. Diabetes Research and Clinical Practice 200984 e21-e23. (https://doi.org/10.1016/j.diabres.2009.02.007)

7 Zhao TY, Li F \& Xiong ZY. Frequent reoccurrence of hypoglycemia in a type 2 diabetic patient with insulin antibodies. Molecular Diagnosis and Therapy 201014 237-241. (https://doi.org/10.2165/11538490000000000-00000)

8 Itoh A, Saisho Y, Mitsuishi M, Oikawa Y, Kawai T, Tanaka M, Shimada A \& Itoh H. Insulin glulisine may ameliorate nocturnal hypoglycemia related to insulin antibody - a case report. Diabetes Research and Clinical Practice 201194 e53-e54; discussion e55. (https://doi.org/10.1016/j.diabres.2011.04.001)

9 Hattori N, Duhita MR, Mukai A, Matsueda M \& Shimatsu A. Development of insulin antibodies and changes in titers over a longterm period in patients with type 2 diabetes. Clinica Chimica Acta 2014433 135-138. (https://doi.org/10.1016/j.cca.2014.03.008)

10 Hu X, Ma X, Wang X, Zhao X, Xu X, Gong H, Chen F \& Sun J. Insulin antibodies in patients with type 2 diabetic receiving recombinant human insulin injection: a report of 12 cases. Annales d'Endocrinologie 201576 694-697. (https://doi.org/10.1016/j. ando.2015.10.004)
11 Li R, Mao J, Yu K, Wang L, Hu M \& Xu L. Medical nutrition therapy is effective in the management of hypoglycemia caused by insulin antibodies: a case report and literature review. Journal of the American College of Nutrition 201635 86-90. (https://doi.org/10.1080/0731572 4.2014.976673)

12 Quan H, Tan H, Li Q, Li J \& Li S. Immunological hypoglycemia associated with insulin antibodies induced by exogenous insulin in 11 Chinese patients with diabetes. Journal of Diabetes Research 2015 2015 746271. (https://doi.org/10.1155/2015/746271)

13 Uchigata Y \& Hirata Y. Insulin autoimmune syndrome (IAS, Hirata disease). Annales de Medecine Interne 1999150 245-253.

14 Lahtela JT, Knip M, Paul R, Antonen J \& Salmi J. Severe antibodymediated human insulin resistance: successful treatment with the insulin analog lispro. A case report. Diabetes Care 199720 71-73. (https://doi.org/10.2337/diacare.20.1.71)

15 Davidson JK \& DeBra DW. Immunologic insulin resistance. Diabetes 197827 307-318. (https://doi.org/10.2337/diab.27.3.307)

16 Witters LA, Ohman JL, Weir GC, Raymond LW \& Lowell FC. Insulin antibodies in the pathogenesis of insulin allergy and resistance. American Journal of Medicine 197763 703-709. (https://doi. org/10.1016/0002-9343(77)90155-3)

17 Koyama R, Nakanishi K, Kato M, Yamashita S, Kuwahara H \& Katori H. Hypoglycemia and hyperglycemia due to insulin antibodies against therapeutic human insulin: treatment with double filtration plasmapheresis and prednisolone. American Journal of the Medical Sciences 2005329 259-264. (https://doi.org/10.1097/00000441200505000-00007)

18 Kim MR, Sheeler LR, Mansharamani N, Haug MT, Faiman C \& Gupta MK. Insulin antibodies and hypoglycemia in diabetic patients. Can a quantitative analysis of antibody binding predict the risk of hypoglycemia? Endocrine 19976 285-291. (https://doi.org/10.1007/ BF02820505)

19 Andersen OO. Clinical significance of anti-insulin-antibodies. Acta Endocrinologica Supplementum 1976205 231-240.

20 Fineberg SE, Kawabata T, Finco-Kent D, Liu C \& Krasner A. Antibody response to inhaled insulin in patients with type 1 or type 2 diabetes. An analysis of initial phase II and III inhaled insulin (Exubera) trials and a two-year extension trial. Journal of Clinical Endocrinology and Metabolism 200590 3287-3294. (https://doi.org/10.1210/jc.20042229)

21 Devlin JG. Evidence for the existence of an IgM immuno-globulin to insulin. Irish Journal of Medical Science 19666 507-510. (https://doi. org/10.1007/BF02943219)

22 Faulk WP, Karam JH \& Fudenberg HH. Human anti-insulin antibodies. Journal of Immunology $1971 \mathbf{1 0 6} 1112-1116$.

23 Grammer LC, Roberts M, Buchanan TA, Fitzsimons R, Metzger BE \& Patterson R. Specificity of immunoglobulin E and immunoglobulin G against human (recombinant DNA) insulin in human insulin allergy and resistance. Journal of Laboratory and Clinical Medicine 1987109 141-146.

24 Kumar D. Anti-insulin IgE in diabetics. Journal of Clinical Endocrinology and Metabolism 197745 1159-1164. (https://doi. org/10.1210/jcem-45-6-1159)

25 Reisman RE, Wicher K \& Arbesman CE. Immunotherapy with antigen E. Journal of Allergy 196944 82-95. (https://doi. org/10.1016/0021-8707(69)90004-5)

26 Patterson R, Roberts M \& Grammer LC. Insulin allergy: re-evaluation after two decades. Annals of Allergy 199064 459-462.

27 Hamilton RG, Rendell M \& Adkinson NF Jr. Serological analysis of human IgG and IgE anti-insulin antibodies by solid-phase radioimmunoassays. Journal of Laboratory and Clinical Medicine 1980 96 1022-1036.

28 Grammer L. Insulin allergy. Clinical Reviews in Allergy 19864 189-200. (https://doi.org/10.1007/BF02993163)

29 deShazo RD, Mather P, Grant W, Carrington D, Frentz JM, Lueg M, Lauritano AA \& Falholt K. Evaluation of patients with local reactions

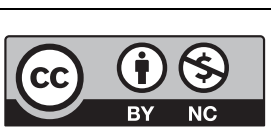

This work is licensed under a Creative Commons Attribution-NonCommercial 4.0 International License. 
to insulin with skin tests and in vitro techniques. Diabetes Care 1987 10 330-336. (https://doi.org/10.2337/diacare.10.3.330)

30 Lieberman P, Patterson R, Metz R \& Ucena G. Allergic reactions to insulin. JAMA 1971215 1106-1112. (https://doi.org/10.1001/ jama.1971.03180200030006)

31 Sodoyez-Goffaux F, Koch M, Dozio N, Brandenburg D \& Sodoyez JC. Advantages and pitfalls of radioimmune and enzyme linked immunosorbent assays of insulin antibodies. Diabetologia 198831 694-702. (https://doi.org/10.1007/BF00278754)

32 Stumpo RR, Llera AS, Cardoso AI \& Poskus E. Solid versus liquid phase assays in detection of insulin antibodies. Influence of iodination site on labelled insulin binding. Journal of Immunological Methods 1994169 241-249. (https://doi.org/10.1016/00221759(94)90268-2)

33 Brooks-Worrell BM, Nielson D \& Palmer JP. Insulin autoantibodies and insulin antibodies have similar binding characteristics. Proceedings of the Association of American Physicians 1999111 92-96. (https://doi.org/10.1046/j.1525-1381.1999.09114.x)

34 Kure M, Katsura Y, Kosano H, Noritake M, Watanabe T, Iwaki Y, Nishigori H \& Matsuoka T. A trial to assess the amount of insulin antibodies in diabetic patients by surface plasmon resonance. Internal Medicine 200544 100-106. (https://doi.org/10.2169/ internalmedicine.44.100)

35 Trabucchi A, Iacono RF, Guerra LL, Faccinetti NI, Krochik AG, Arriazu MC, Poskus E \& Valdez SN. Characterization of insulin antibodies by Surface Plasmon Resonance in two clinical cases: brittle diabetes and insulin autoimmune syndrome. PLOS ONE $2013 \mathbf{8}$ e84099. (https://doi.org/10.1371/journal.pone.0084099)

36 Oak S, Phan TH, Gilliam LK, Hirsch IB \& Hampe CS. Animal insulin therapy induces a biased insulin antibody response that persists for years after introduction of human insulin. Acta Diabetologica 201047 131-135. (https://doi.org/10.1007/s00592-009-0135-2)

37 Sauerborn M, Brinks V, Jiskoot W \& Schellekens H. Immunological mechanism underlying the immune response to recombinant human protein therapeutics. Trends in Pharmacological Sciences 2010 31 53-59. (https://doi.org/10.1016/j.tips.2009.11.001)

38 Dailey G, Rosenstock J, Moses RG \& Ways K. Insulin glulisine provides improved glycemic control in patients with type 2 diabetes. Diabetes Care 200427 2363-2368. (https://doi.org/10.2337/ diacare.27.10.2363)

39 Fineberg SE, Huang J, Brunelle R, Gulliya KS \& Anderson JH Jr. Effect of long-term exposure to insulin lispro on the induction of antibody response in patients with type 1 or type 2 diabetes. Diabetes Care 200326 89-96. (https://doi.org/10.2337/diacare.26.1.89)

40 Lindholm A, Jensen LB, Home PD, Raskin P, Boehm BO \& Rastam J. Immune responses to insulin aspart and biphasic insulin aspart in people with type 1 and type 2 diabetes. Diabetes Care $2002 \mathbf{2 5}$ 876-882. (https://doi.org/10.2337/diacare.25.5.876)

41 Mianowska B, Szadkowska A, Pietrzak I, Zmyslowska A, Wegner O, Tomczonek J, Bodalski J \& Mlynarski W. Immunogenicity of different brands of human insulin and rapid-acting insulin analogs in insulinnaive children with type 1 diabetes. Pediatric Diabetes 201112 78-84. (https://doi.org/10.1111/j.1399-5448.2010.00659.x)

42 Pieber TR, Eugene-Jolchine I \& Derobert E. Efficacy and safety of HOE 901 versus NPH insulin in patients with type 1 diabetes. The European Study Group of HOE 901 in type 1 diabetes. Diabetes Care 200023 157-162. (https://doi.org/10.2337/diacare.23.2.157)

43 Dahl-Jorgensen K, Torjesen P, Hanssen KF, Sandvik L \& Aagenaes O. Increase in insulin antibodies during continuous subcutaneous insulin infusion and multiple-injection therapy in contrast to conventional treatment. Diabetes 198736 1-5. (https://doi. org/10.2337/diab.36.1.1)

44 Jeandidier N, Boivin S, Sapin R, Rosart-Ortega F, Uring-Lambert B, Reville P \& Pinget M. Immunogenicity of intraperitoneal insulin infusion using programmable implantable devices. Diabetologia 1995 38 577-584. (https://doi.org/10.1007/BF00400727)
45 Olsen CL, Chan E, Turner DS, Iravani M, Nagy M, Selam JL, Wong ND, Waxman K \& Charles MA. Insulin antibody responses after long-term intraperitoneal insulin administration via implantable programmable insulin delivery systems. Diabetes Care 199417 169-176. (https://doi.org/10.2337/diacare.17.3.169)

46 Jeandidier N, Boullu S, Busch-Brafin MS, Chabrier G, Sapin R, Gasser F \& Pinget M. Comparison of antigenicity of Hoechst 21PH insulin using either implantable intraperitoneal pump or subcutaneous external pump infusion in type 1 diabetic patients. Diabetes Care 200225 84-88. (https://doi.org/10.2337/ diacare.25.1.84)

47 Radermecker RP, Renard E \& Scheen AJ. Circulating insulin antibodies: influence of continuous subcutaneous or intraperitoneal insulin infusion, and impact on glucose control. Diabetes/Metabolism Research and Reviews 200925 491-501. (https://doi.org/10.1002/ dmrr.961)

48 Mastrandrea LD. Inhaled insulin: overview of a novel route of insulin administration. Vascular Health and Risk Management 20106 47-58. (https://doi.org/10.2147/VHRM.S6098)

49 Heise T, Bott S, Tusek C, Stephan JA, Kawabata T, Finco-Kent D, Liu C $\&$ Krasner A. The effect of insulin antibodies on the metabolic action of inhaled and subcutaneous insulin: a prospective randomized pharmacodynamic study. Diabetes Care 200528 2161-2169. (https://doi.org/10.2337/diacare.28.9.2161)

50 Teeter JG \& Riese RJ. Dissociation of lung function changes with humoral immunity during inhaled human insulin therapy. American Journal of Respiratory and Critical Care Medicine 2006173 1194-1200. (https://doi.org/10.1164/rccm.200512-1861OC)

51 Hermansen K, Ronnemaa T, Petersen AH, Bellaire S \& Adamson U. Intensive therapy with inhaled insulin via the AERx insulin diabetes management system: a 12-week proof-of-concept trial in patients with type 2 diabetes. Diabetes Care 200427 162-167. (https://doi. org/10.2337/diacare.27.1.162)

52 Ang E, Lawrence MK, Heilmann CR, Ferguson JA, Tobian JA, Webb DM \& Berclaz PY. Safety and efficacy of AIR inhaled insulin compared with subcutaneous insulin in patients having diabetes and asthma: a 12-month, randomized, noninferiority trial. Diabetes Technology and Therapeutics 200911 (Supplement 2) S35-S44. (https://doi.org/10.1089/dia.2009.0054)

53 Garg SK, Mathieu C, Rais N, Gao H, Tobian JA, Gates JR, Ferguson JA, Webb DM \& Berclaz PY. Two-year efficacy and safety of AIR inhaled insulin in patients with type 1 diabetes: an open-label randomized controlled trial. Diabetes Technology and Therapeutics 200911 (Supplement 2) S5-S16. (https://doi.org/10.1089/dia.2009.0040)

54 American Medical Association. An inhaled insulin (Afrezza). JAMA 2015313 2176-2177. (https://doi.org/10.1001/jama.2015.5634)

55 Kahn CR, Mann D, Rosenthal AS, Galloway JA, Johnson AH \& Mendell N. The immune response to insulin in man. Interaction of HLA alloantigens and the development of the immune response. Diabetes 198231 716-723. (https://doi.org/10.2337/ diab.31.8.716)

56 Reeves WG, Gelsthorpe K, Van der Minne P, Torensma R \& Tattersall RB. HLA phenotype and insulin antibody production. Clinical and Experimental Immunology 198457 443-448.

57 Asplin CM, Dornan TL, Raghu PK, Hansen JA \& Palmer JP. The antibody response to insulin therapy. A prospective study in HLAtyped insulin-dependent diabetic subjects. Diabetes 198433 966-969. (https://doi.org/10.2337/diab.33.10.966)

58 Yoshida M, Asai M, Miyata M, Ogawa K, Maeda H \& Oiso Y. Combination therapy with liraglutide and sulfonylurea for a type 2 diabetic patient with high titer of anti-insulin antibodies produced by insulin therapy. Diabetes Research and Clinical Practice 201296 e55-e56. (https://doi.org/10.1016/j.diabres.2011.12.024)

59 Yoshida M, Murakami M, Ogawa K, Asai M, Miyata M, Maeda H \& Oiso Y. Repeated hypoglycemia caused by the overproduction of anti-insulin antibodies and isolated ACTH deficiency in a type 2

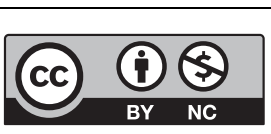

This work is licensed under a Creative Commons Attribution-NonCommercial 4.0 International License. 
diabetic patient receiving insulin therapy. Diabetes Care 201336 e22. (https://doi.org/10.2337/dc12-1565)

60 Fineberg N, Fineberg S \& Galloway J. Does age at initiation of insulin therapy determine who will develop an immune response. Diabetes 199241 (Supplement 1) 191A.

61 He H, Yang X, Lv X, Wang C, Chen D, Li X \& Ran X. The difference of blood glucose fluctuation in type 2 diabetes mellitus patients with positive and negative insulin autoantibodies. Chinese Journal of Multiple Organ Diseases in the Elderly 201211 645-649.

62 Wang X, Xu XL, Zhao XL, Ma XW, Yu H, Gong H, Zhang SR \& Chen FL. Hypoglycemia due to insulin binding antibodies in a patient with insulin-treated type 2 diabetes and Graves' disease. Endocrine 201343 236-237. (https://doi.org/10.1007/s12020-012-9721-0)

63 Ganz MA, Unterman T, Roberts M, Uy R, Sahgal S, Samter M \& Grammer LC. Resistance and allergy to recombinant human insulin. Journal of Allergy and Clinical Immunology 199086 45-51. (https://doi. org/10.1016/S0091-6749(05)80122-8)

64 Asai M, Kodera T, Ishizeki K, Uebori S, Kashiwaya T, Itoh H \& Makino I. Insulin lispro reduces insulin antibodies in a patient with type 2 diabetes with immunological insulin resistance. Diabetes Research and Clinical Practice 200361 89-92. (https://doi. org/10.1016/S0168-8227(03)00105-0)

65 Hara K, Tobe K, Uchigata Y, Nakazono M, Yasuda K, Terauchi Y, Iwamoto Y, Akanuma Y, Kimura S \& Kadowaki T. Antibody-mediated insulin resistance treated by cessation of insulin administration. Internal Medicine 200039 143-145. (https://doi.org/10.2169/ internalmedicine.39.143)

66 Jaeger C, Eckhard M, Brendel MD \& Bretzel RG. Diagnostic algorithm and management of immune-mediated complications associated with subcutaneous insulin therapy. Experimental and Clinical Endocrinology and Diabetes 2004112 416-421. (https://doi. org/10.1210/jc.2003-031822)

67 Kronmal RA, Barzilay JI, Tracy RP, Savage PJ, Orchard TJ \& Burke GL. The relationship of fasting serum radioimmune insulin levels to incident coronary heart disease in an insulin-treated diabetic cohort. Journal of Clinical Endocrinology and Metabolism 200489 2852-2858. (https://doi.org/10.1210/jc.2003-031822)

68 Li F, Wu Z, Chi Q, Qiao X \& Wang S. Study about the immunogenicity of recombinant human insulin in treatment of type 2 diabetes mellitus. Chinese Journal of Clinicians 20137 9081-9085.

69 Seewi O, Jaeger C, Bretzel RG \& Schonau E. Insulin binding to antibodies is a risk factor for inexplicable severe hypoglycaemia in children with type-1 diabetes mellitus. Experimental and Clinical Endocrinology and Diabetes 2008116 293-297. (https://doi. org/10.1055/s-2007-1004565)

70 Fallucca F, Maldonato A, Iavicoli M, Di Rollo G, Di Biase N, Napoli A, De Vecchis P, Sciullo E, Gerlini G \& Pachi A. Influence of maternal metabolic control and insulin antibodies on neonatal complications and B cell function in infants of diabetic mothers. Diabetes Research and Clinical Practice 19897 277-284. (https://doi.org/10.1016/01688227(89)90016-8)

71 Murata K, Toyoda N \& Sugiyama Y. The effects of insulin antibodies during diabetic pregnancy on newborn infants. Asia-Oceania Journal of Obstetrics and Gynaecology 199016 115-122. (https://doi. org/10.1111/j.1447-0756.1990.tb00012.x)

72 Ionescu-Tirgoviste C, Mincu I, Simionescu L, Cheta D, Mirodon Z, Santu E, Popa E \& Birnea A. Disappearance rate of insulin antibodies after discontinuing insulin treatment in 42 type 2 (non-insulindependent) diabetic patients. Diabetologia 198427 592-595. (https://doi.org/10.1007/BF00276974)

73 Maneschi F, Fineberg SE \& Kohner EM. Successful treatment of immune-mediated insulin resistance by human insulin (recombinant DNA). Diabetes Care 19825 (Supplement 2) 175-179. (https://doi. org/10.2337/diacare.5.2.S175)

74 Yanai H, Adachi H \& Hamasaki H. Diabetic ketosis caused by the insulin analog aspart-induced anti-insulin antibody: successful treatment with the newest insulin analog glulisine. Diabetes Care 201134 e108. (https://doi.org/10.2337/dc11-0326)

75 Suzuki K, Hirayama S \& Ito S. A case of a non-insulin dependent diabetic patient with regular spontaneous hypoglycemic attacks, which were due to insulin-binding antibodies induced by human insulin therapy. Tohoku Journal of Experimental Medicine 1997182 163-173. (https://doi.org/10.1620/tjem.182.163)

76 Matsuyoshi A, Shimoda S, Tsuruzoe K, Taketa K, Chirioka T, Sakamoto F, Sakakida M, Miyamura N \& Araki E. A case of slowly progressive type 1 diabetes with unstable glycemic control caused by unusual insulin antibody and successfully treated with steroid therapy. Diabetes Research and Clinical Practice 200672 238-243. (https://doi.org/10.1016/j.diabres.2005.10.018)

77 Honda M, Kawashima Y, Kawamura H, Fujikawa H, Kikuchi K, Ohashi H, Mori Y, Miyakawa H \& Ishibashi M. Acute liver dysfunction complicated with uncontrollable glycemia due to insulin antibody: successful treatment with glucocorticoid and lispro insulin. Internal Medicine 200645 1225-1229. (https://doi.org/10.2169/ internalmedicine.45.6009)

78 Greenfield JR, Tuthill A, Soos MA, Semple RK, Halsall DJ, Chaudhry A \& O'Rahilly S. Severe insulin resistance due to anti-insulin antibodies: response to plasma exchange and immunosuppressive therapy. Diabetic Medicine 200926 79-82. (https://doi.org/10.1111/ j.1464-5491.2008.02621.x)

79 Macleisha SA, Wallacea S, Madhuna ZR \& Hostoffer JA. Treatment of hypoglycemia with intramuscular immunoglobulin in insulin dependent-diabetics with insulin antibodies. Journal of Allergy and Clinical Immunology 2009119 S18.

Received in final form 1 December 2017

Accepted 12 December 2017

Accepted Preprint published online 12 December 2017 http://www.endocrineconnections.org https://doi.org/10.1530/EC-17-0309
○ 2018 The authors Published by Bioscientifica Ltd

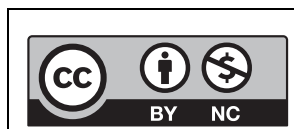

This work is licensed under a Creative Commons Attribution-NonCommercial 4.0 International License. 